\title{
LA GESTIÓN ANTI-SOCIOLÓGICA Y TECNO-EXPERTA DE LA PANDEMIA DEL COVID- 19
}

\section{The anti-sociological and techno-expert management of Covid-19 pandemic}

\author{
Danilo Martuccelli* \\ Universidad de París (Francia) y Universidad Diego Portales (Chile)
}

\section{Palabras clave}

Anti-sociología

Sociabilidad

Expertos

Pandemia

Covid-19

\section{Keywords}

Anti-sociology

Sociability

Experts

Pandemic

Covid-19
RESUMEN: El artículo propone un conjunto de reflexiones críticas sobre la gestión tecnoexperta de la pandemia del covid-19. Apoyándose en las dos grandes estrategias espaciales de prevención puestas en práctica, los confinamientos y los distanciamientos, el texto no se interesa ni en los diferenciales de resultados obtenidos a nivel nacional, ni en las razones que llevaron a su implementación. Lo que se analiza son los presupuestos y los imaginarios sociales subyacentes a las decisiones tomadas, la homogeneidad de las medidas que fueron generalizadas con muy escasa atención hacia los contextos locales, y los ideales de sociabilidad que se movilizaron. Se destaca, sobre todo, la tensión entre lo presencial y lo virtual, entre una sociabilidad fundada en la interacción y una sociabilidad que tendencialmente se concibe desde la conectividad generalizada, y la manera en que ello rediseña potencialmente toda una nueva jerarquía social de oficios y de actividades. Es este conjunto dispar de imaginarios, tendencias y medidas que el artículo critica por su carácter anti-sociológico y descontextualizado.

ABSTRACT: The article proposes a set of critical reflections on the techno-expert management of the covid-19 pandemic. Leaning on the two major prevention strategies put into practice, quarantines and distancing, the text is not interested in the differentials results at the national level, nor in the reasons that led to their implementation. What it is analyzed are the presuppositions and social imaginaries underlying the decisions made, the homogeneity of the measures that were generalized with very little attention to local contexts, and the ideals of sociability that were mobilized. Above all the article analyzes the tension between the face-to-face and the virtual relations, between a sociability founded on interaction and a sociability that tends to be conceived out from generalized connectivity, as well as the way in which this potentially redesigns a whole new social hierarchy of trades and activities. It is this disparate set of imaginaries, trends and measures that the article criticizes for its anti-sociological and decontextualized nature.

\footnotetext{
* Correspondencia a / Correspondence to: Danilo Martuccelli. Université de Paris-CERLIS. 45, rue des Satins Pères (75006 Paris-France) - danilomartuccelli@ gmail.com - http://orcid.org/0000-0001-5940-8949.

Cómo citar / How to cite: Martuccelli, Danilo (2021). «La gestión anti-sociológica y tecno-experta de la pandemia del Covid-19». Papeles del CEIC, vol. 2021/1, papel 246, 1-16. (http://dx.doi.org/10.1387/pceic.21916).
}

Fecha de recepción: julio, 2020 / Fecha aceptación: noviembre, 2020.

ISSN 1695-6494 / ㄷ 2021 UPV/EHU 
Epidemias de origen viral se han dado varias veces en la historia y las cuarentenas han sido desde hace siglos una de las principales respuestas ante ellas ${ }^{1}$. Sin embargo, esta continuidad aparente no debe llevar a descuidar las grandes especificidades de la gestión de la pandemia del covid-19 sobre todo en lo relativo al papel de los expertos. Recordémoslo: los datos producidos en los primeros meses del 2020 tuvieron un efecto central en las decisiones tomadas. Una de las más influyentes previsiones entonces disponible, la del Imperial College de Londres, estimó que la pandemia produciría unos 40 millones de muertos en el mundo. Es basándose en estas cifras que los gobiernos tomaron, presos por el pánico, la decisión de los confinamientos.

Primer acto: una parte considerable del mundo entró en cuarentena a causa de una estimación sobre el número de muertos potenciales. La progresión de las cifras fue importante. Si se dejan de lado las polémicas sobre el número exacto de muertos, el 1 de julio de 2020 los fallecimientos eran de unos 516.000 a nivel mundial y el 1 de octubre de 2020 ya se habia superado la cifra del millón de muertos, en un momento en el cual la pandemia está todavía muy lejos de ser controlada. Sin embargo, ambas cifras son mucho menores de lo previsto por aquellos informes (poco más del 1,3\% de la estimación del Imperial College de Londres en el mes de julio y del $2,5 \%$ en octubre). Esto es también, sin duda, un resultado de las diversas políticas sanitarias que se implementaron con resultados nacionales muy disímiles².

A pesar de la importancia de esta cuestión, en este artículo no es ni la justeza de las decisiones ni los resultados comparados de las distintas estrategias nacionales lo que nos interesará problematizar ${ }^{3}$, sino los presupuestos anti-sociológicos de la gestión tecno-experta de la pandemia. La evolución temporal de las situaciones nacionales es tal (en número de contagios, fallecidos, control de los clusters, segunda ola) que en este texto tomaremos arbitrariamente como fecha de corte del análisis el primero de octubre de $2020^{4}$.

La tesis que someteremos a prueba es el carácter anti-sociológico de muchos de los postulados expertos con los que se enfrentó sanitariamente la pandemia, privilegiando dos grandes temáticas de carácter social y espacial: los confinamientos (a veces denominados cuarentenas) y los distanciamientos. Nuestro objetivo no es establecer un muy dudoso ránking de performances entre países, sino analizar los resortes subyacentes a las medidas tecno-expertas

1 Este trabajo se benefició del apoyo financiero de la Iniciativa Científica Milenio de la Agencia Nacional de Investigación y Desarrollo (ANID) de Chile adjudicado al Centro Núcleo Milenio Autoridad y Asimetrías de Poder, NCS17_007.

2 Siempre según un estudio del Imperial College de Londres de comienzos de junio del 2020, las medidas de confinamiento permitieron salvar la vida de 3,1 millones de personas en 11 países europeos. En este argumento, la estimación no se cumplió debido a los efectos disuasivos de la propia estimación. Según ella la comparación entre los casos reales de deceso y la estimación establece el número de vidas salvadas. Una demostración que busca clausurar las posibilidades de impugnación. Otros, siempre a partir de tendencias, muestran los miles de vidas que habrían podido salvarse con otras medidas. No es anecdótico: la generalización de argumentos contrafactuales es uno de los grandes rasgos de la razón tecno-experta contemporánea.

3 Prestigiosas revistas anglosajonas (The Economist, The Financial Times, Bloomberg, Time...) produjeron rankings nacionales a partir de un número reducido de indicadores. The Economist Intelligence Unit pudo así, por ejemplo, publicar el 17 de junio de 2020 una clasificación sobre «How well have OECD countries responded to the coronavirus crisis». La lectura de estos rankings deja perplejo a cualquier observador: muchas veces establecidos a través de tres criterios, por lo general distintos entre los diversos estudios, un mismo país ve su posición variar sustancialmente de una clasificación a otra...

4 No es un tema menor. La diversidad de las secuencias de la pandemia son tales que muchos de los análisis precipitados que se hicieron de ellas, sobre todo por parte de muy mediáticos intelectuales contemporáneos (Agamben, Zizek, Paul B. Preciado, Butler, Byung-Chul Han, etc.), revelaron rápidamente sus límites y contraverdades. Los textos fueron reunidos en Sopa de Wuhan (2020). 
tomadas. Si con el paso de los meses las políticas sanitarias evolucionaron al contacto de las situaciones locales, como intentaremos mostrarlo, esto solo se hizo desde el marco de una visión profundamente unitaria.

Lo que nos interesa problematizar en este artículo son pues los imaginarios y los presupuestos subyacentes a las soluciones institucionales. Como las medidas de shock económico, los confinamientos fueron generalizados con muy escasa atención hacia los contextos locales: las modalidades de la sociabilidad, la dificultad de las instituciones públicas para llegar a ciertos sectores, la ausencia de recursos públicos para poder otorgar apoyos, su sostenibilidad económica en el tiempo (porcentaje de trabajadores informales o independientes, con ingresos diarios), la exigüidad de muchas viviendas, la soledad o a la inversa el alto número de personas residiendo conjuntamente en pequeñas viviendas, las diferentes necesidades psicológicas de los individuos. Detrás de esta decisión, la idea que prima, propia a la expertocracia mundial, es que las mismas medidas pueden aplicarse en todos lados. Si hay una disciplina que en su médula epistemológica contradice esta visión es justamente la sociología y su exigencia imperativa de contextualización (Passeron, 1991).

El objetivo de este artículo -el estudio crítico del imaginario tecno-experto de la pandemia- da cuenta del modo de argumentación que seguiremos. Para mostrar la similitud de este imaginario, la argumentación se apoyará sobre un gran número de casos y ejemplos tomados de varias experiencias nacionales. El análisis no se centrará por eso en el estudio de implementaciones concretas a nivel de las políticas públicas (lo que exigiría múltiples monografías), sino en la permanencia de los imaginarios anti-sociológicos movilizados durante la pandemia. Un imaginario que es particularmente visible y contraproducente a nivel de la representación de la sociabilidad y sus traducciones espaciales.

Si las cuarentenas no son nuevas, las estrategias tanto de la OMS como de muchos gobiernos contra la pandemia del covid-19 asombran por su visión anti-sociológica. Primer aspecto: en varios países, los ciudadanos no fueron participes de la gestión de la pandemia. El heroísmo ciudadano (tan puesto en escena por spots publicitarios y mensajes gubernamentales) consistió en quedarse aislado y confinado. Fue el precio que impuso la militarización de lo sanitario (la «primera línea», la "guerra» contra el virus).

Por supuesto, los modos de infección explican una buena parte de las diferencias, pero el contraste es radical con lo que aconteció con el HIV-Sida en la década de $1980^{5}$. Frente al Sida, la movilización de la comunidad homosexual fue decisiva en el rechazo de los centros de reclusión para los enfermos, en la definición de las personas a riesgo (en ciertos países, aquel que tenía más de dos parejas sexuales por año, independientemente de toda orientación sexual), en el tipo de campañas de prevención que se hicieron. Mientras se avanzaba en la búsqueda de un tratamiento, una vacuna (que hasta la fecha no está disponible) o en el conocimiento del virus, la principal solución fue social y comunitaria. En nombre de los valo-

5 Tanto más que a comienzos de julio de 2020, la OMS terminó por reconocer la posibilidad de una transmisión del virus del covid-19 por vía aérea, lo que no es el caso con el virus del Sida. 
res de la democracia se aceptó (no sin discriminaciones, no sin abusos) enfrentar los riesgos de una enfermedad mortal y contagiosa preservando los grandes principios de una sociedad abierta.

La gestión del covid-19 ha sido casi opuesta: no solo no se intentó movilizar a los actores sociales, sino que lo esencial de la estrategia fue en muchos países organizar la desmovilización de los ciudadanos merced a confinamientos generalizados ${ }^{6}$. En menos de 40 años se pasó de una innovadora respuesta de la sociedad civil a una gestión tecno-experta y desmovilizadora (con fuertes sanciones y controles policiales). Es posible formular la hipótesis que esta diferencia se explica, al menos en parte, por el incremento de poder que ha adquirido la filosofía de las best practices y de los razonamientos tecno-expertos en las últimas décadas (Martuccelli, 2010).

Bajo la impronta de esta perspectiva, los gobiernos democráticos en Europa o en América Latina imitaron (o siguieron) la gestión autoritaria que el gobierno chino impuso a través de la gran cuarentena generalizada en la ciudad de Wuhan. Ciertamente, muchas de las medidas autoritarias que se practicaron en ese país no fueron remedadas (traslado obligatorio en residencias sanitarias en caso de contagio, muchas veces impuestas manu militari a personas que rechazaban ser desplazadas de sus viviendas; utilización intensiva de aplicaciones digitales de trazabilidad sin respeto de las libertades básicas para circunscribir la expansión del virus; etc.). Pero sí se adoptó lo esencial: la cuarentena generalizada como principal respuesta a la pandemia. Esta elección congeló toda imaginación colectiva alternativa. Puede que incluso esta solución haya tenido un efecto en la muy asombrosa no recomendación del uso de mascarillas (o barbijos) durante meses por parte de muchos gobiernos y de la OMS (lo que, dicho sea de paso, sí impuso muy rápidamente el gobierno chino).

El encierro de los ciudadanos se convirtió en la gran respuesta de las democracias. Se trató de una paradójica figura de movilización coactiva generalizada propia a las sociedades modernas. El impresionante número de personas confinadas supuso una diferencia radical con el pasado: ¿existe hybris más grande de poder que la de paralizar simultáneamente «toda» la actividad mundial? Solo la modernidad pudo imaginar algo así.

Muchas encuestas muestran por doquier, desde hace décadas, la desconfianza creciente de los ciudadanos hacia las instituciones y los actores políticos. Sin embargo, no es este el problema principal de las democracias. La gestión tecno-experta de la pandemia ha revelado otro mal mucho más corrosivo: la desconfianza de los gobiernos hacia sus ciudadanos.

En este punto, un contraste perturbador se produjo. Una importante faceta de la respuesta de varios gobiernos asiáticos fue la movilización disciplinada (y muchas veces coercitiva) de la población. En el caso de muchos regímenes democráticos, los ciudadanos no fueron hechos partícipes o solo lo fueron muy escasamente. Se reveló así una reticencia gubernamental hacia la ciudadanía que no es sin duda ajena a los malestares de muchas sociedades democráticas actuales y a la expansión de los denominados populismos (Tarragoni, 2019).

Las razones de esta desconfianza gubernamental son plurales, pero dos grandes fuentes destacan. Por un lado, el despotismo ilustrado ha sido reinventado por la expertocracia: eco-

6 Esto no impidió formas de autoorganización, como en ciertos barrios periféricos del Gran Buenos Aires, en donde los habitantes autofinanciaron colectivamente campañas sanitarias, o la reactivación de asociaciones barriales y comunales en muchas ciudades latinoamericanas luego de décadas de programas técnicos focales. 
nomía, ecología o pandemia, siempre es cuestión de no consultar ni hacer partícipes a los ciudadanos ignaros. En todos lados, el saber tecno-experto menospreció y desestimó radicalmente el posible valor de los saberes profanos y de la experiencia (Callon, Lascoumes y Barthe, 2001). Por el otro lado, particularmente en América Latina, la pandemia reactivó estereotipos muy viejos entre las élites con respecto a los individuos incívicos y transgresivos. El estereotipo fue movilizado hasta el hartazgo: los ciudadanos, cual menores de edad que requerían ser tutelados, eran "incapaces" de entender la gravedad del virus; tuvieron conductas «irresponsables» (fiestas, reuniones, personas contagiadas que siguieron trabajando); fueron los verdaderos "responsables» del fracaso de las cuarentenas. Aunque esta tendencia fue precoz y masiva en América Latina, tendencias similares también se dieron en Europa e incluso se reforzaron a medida que se hizo patente la llegada de la denominada segunda ola en el otoño de 2020.

No es cuestión de negar problemas concretos, pero sí de destacar lo que subyace a estas representaciones: una gestión tecno-experta desmovilizadora de la sociedad civil. Aquí reside la verdadera afinidad entre la OMS y los gobiernos autoritarios. Los estereotipos sirvieron como prejuicio para explicar el porqué del no respeto de las consignas, cuando la pregunta más justa y apremiante era saber cómo hacer para que un amplio número de ciudadanos disponga de los recursos para poder acatarlas ${ }^{7}$. Esta mirada exigía otro tipo de confianza de los gobiernos hacia las ciudadanías. La cuarentena no fue pues solamente una medida sanitaria. La manera cómo fue instaurada tradujo imaginarios ciudadanos muy distintos. La movilización y el llamado a la responsabilidad activa de los ciudadanos explica que, con o sin confinamiento, ciertos países hayan obtenido, a la fecha del 1 de octubre de 2020, mejores resultados (Vietnam, Nueva Zelanda, Uruguay) ${ }^{8}$.

La anti-sociología de los confinamientos generalizados también se refleja en la representación estandarizada de las sociedades actuales. El que cada cual realice la cuarentena en su residencia presuponía que todos tenían en ellas las condiciones materiales de hábitat para hacerlo; que para todos la residencia era un lugar de refugio (descuidando la violencia doméstica, pero también las múltiples dificultades de convivencia de las muy distintas configuraciones familiares); que durante el confinamiento todos tenían las mismas competencias para ocupar el tiempo (borrando necesidades y capacidades distintas entre adolescentes y adultos, entre trabajadores habituados a actividades más o menos sedentarias, etc.); que todos podian teletrabajar o estudiar desde sus casas.

En la noche de la gestión tecno-experta de la pandemia todos los gatos fueron pardos. Con un bemol. Hubo una conciencia de la diversidad de las situaciones, pero única o esencialmente de índole económica. Si las respuestas tuvieron relativamente en cuenta la diversidad de las situaciones económicas (cajas de alimentos o ayudas diferencialmente otorgadas en función de los niveles de ingresos), esto contrasta fuertemente con la homogeneización antisociológica que presupuso el confinamiento generalizado a nivel de las sociabilidades. Poco o nada se hizo en esta dirección (en muy pocos países se incentivaron «burbujas» de sociabili-

7 Una encuesta de finales del mes de mayo de 2020 arrojó que los peruanos le temían más al contagio del virus que al hambre. Bajo este parámetro, la salida transgresiva de la cuarentena no fue el fruto de un sentimiento de invulnerabilidad. Todo lo contrario: a pesar del gran temor a la epidemia, por razones diversas, los individuos salieron a las calles.

8 Casos nacionales muy distintos de los países en donde los gobiernos negaron, temporal o durablemente, el peligro de la epidemia como Brasil, Estados Unidos, Rusia, México o Reino Unido. Para un análisis de las similitudes y diferencias de las gestiones nacionales en América Latina, ver: Martuccelli, 2020. 
dad entre pequeños grupos). Si algunos expertos lamentaron la falta de épica colectiva en el enfrentamiento de la pandemia, sus soluciones siempre siguieron siendo rigurosamente técnicas: trazabilidad, aplicaciones digitales, controles, más datos.

La diversidad de situaciones locales desafiaba toda posibilidad de inteligencia global. Esto es lo que desconoció la mirada tecno-experta y lo que, en mucho, no pudo ser corregido dado el déficit democrático que se impuso. Esto es lo que progresivamente se tuvo que reconocer. Los confinamientos fueron muy distintos para los hombres y las mujeres (dada la habitual mayor demanda de disponibilidad a la que las mujeres están sujetas en el espacio doméstico y su menor privacidad). Pero también fueron muy diferentes según las configuraciones familiares y particularmente dura para las personas viviendo solas o en las familias monoparentales con menores de edad. Lo fueron también para los adultos mayores o para las personas que conviven con ellos, dado los temores acentuados de contagio. En fin, en una lista que puede alargarse a voluntad, la infancia y la adolescencia como grupos etarios percibieron, dadas sus especificas necesidades de sociabilidad, como particularmente problemáticos los confinamientos.

Los confinamientos fueron la solución experta promovida por los expertos para ganar tiempo con el fin de subsanar errores expertos anteriores. Ciertamente, en la dinámica de los errores previos y el confinamiento-como-solución no son los mismos expertos los que están en cuestión - y tras ello se jugó, durante la epidemia, la rivalidad entre la razón económica y la razón sanitaria9 - La no inversión en el sistema de salud, el cierre de servicios, la reducción del número de camas fue el resultado de políticas de austeridad (o de no inversión pública en países con excedentes presupuestarios) motivadas por ciertas orientaciones económicas. Esta situación no fue similar por doquier, pero se reveló como una tendencia masiva en muchos de los países que vieron sus sistemas de salud colapsar durablemente durante la pandemia. El resultado de estas políticas fue que, en muchos países, el sistema de salud estaba desguarnecido para enfrentar la pandemia (a pesar de tantas voces críticas y de tres brotes epidémicos solo en la última década). Esta miopía economicista experta fue compensada con la mono-respuesta sanitaria experta: Ios confinamientos. Aislar y desmovilizar a la población para ganar tiempo con el fin de ampliar el número de camas, las $\mathrm{UCI}$ (unidades de cuidados intensivos), los equipos respiratorios disponibles o por lo menos extender en el tiempo el número de los contagios. En casi todos los países el confinamiento permitió en efecto aumentar en tiempo real el número de camas UCI disponibles. Sin embargo, como lo reveló la denominada segunda ola o la recrudescencia de los casos, el sistema de salud se reveló demasiado debilitado estructuralmente.

A pesar de las protestas contra las economías en el sector salud desde hace décadas, un grupo de expertos las desestimó en nombre de imperativos económicos. Ante la urgencia de la pandemia, otro grupo de expertos desestimó toda consulta o movilización de la sociedad civil. Con el fin de explorar escenarios de salida a la crisis generada por la pandemia, varios gobiernos formaron comisiones de expertos esencialmente compuestas de economistas. Como en cierta versión religiosa, los expertos - como Dios- están en todos lados y nadie los puede ver. Los expertos están en el origen, la gestión, la solución de los problemas.

Los confinamientos plantearon una paradoja, a saber, la disminución del contagio exigía el aislamiento de los individuos entre sí, pero el éxito de esta medida (más allá de los diferen-

9 A lo que se podría añadir dentro de la razón sanitaria la tensión entre infectólogos y epidemiólogos. 
ciales de recursos de unos y otros) suponía un reforzamiento de los lazos sociales, de la colaboración, del cuidado recíproco (Mora y Tironi, 2020). A su manera, aunque no siempre se explicó con la contundencia que debió ser hecho, las mascarillas (como el preservativo en el caso del Sida) eran tanto o más un signo de cuidado hacia terceros que un acto de autocuidado. Las mascarillas al controlar la emisión de las pequeñas gotas de saliva al hablar protegen más a las personas del entorno que al propio sujeto de su entorno. La pandemia ejemplificó así con un vigor inusitado la centralidad de la dinámica entre lo singular y lo común en las sociedades modernas. Tampoco esto es nuevo, pero la interdependencia entre los individuos ha alcanzado niveles jamás conocidos en el pasado (Martuccelli, 2017).

Aquí también la gestión tecno-experta de la pandemia se reveló profundamente anti-sociológica: solo se pensó la situación desde los riesgos de contagio y no desde las nuevas especificidades e interdependencias de la vida en común. Su complejidad fue desconsiderada en aras de una concepción profundamente desencarnada de los individuos.

En América Latina, más que en Europa, se dieron salidas individualizadas de facto, prematuras y desordenadas de los confinamientos. Los diagnósticos, otra vez, se revelaron profundamente anti-sociológicos. Tanto los que criticaban como los que avalaban estas actitudes redujeron la problemática a una cuestión económica y sanitaria.

Una extraña oposición se elaboró entre la «vida» y la «economía»; a veces entre la salud de las personas de edad y el futuro de los más jóvenes ${ }^{10}$. En estas dicotomías es impactante el carácter anti-sociológico del imaginario de la "vida» sin cualidades de los tecno-expertos. ¿Cómo «la» vida y el confinamiento pudieron esgrimirse como imperativos frente a las exigencias del capitalismo, pero también de las escuelas, las deudas, la sociabilidad, la violencia conyugal? ¿Por qué se decidió en un mundo tan ordinariamente indiferente a las vidas humanas (inmigración, hambre, asesinatos, exclusión) realizar un esfuerzo de tal talla y con tales consecuencias en nombre de "la» vida? ¿Cómo se pudo desestimar hasta este punto las necesidades de los seres humanos como animales gregarios?

La hipótesis de una modernidad sometida a la bio-política y al valor central de «la» vida es menos explicativa que lo que parece (Esposito, 2004). Desestima las rápidas tensiones que se dieron tanto con "la» economía como la diversidad de las posiciones existentes en la opinión pública y a nivel de los gobiernos. Esta perspectiva desestima sobre todo la variedad de las experiencias sociales que se tensaron detrás de esta decisión. La vida en cuarentena significó, por ejemplo, para muchos adultos mayores una prueba extrema. Muchos - sobre todo muchas - la padecieron aisladas, lo que se tradujo por una acentuación de depresiones; otros que pudieron vivirlo en pareja fueron desvitalizados por el confinamiento, lo que probablemente tendrá efectos durables en su sociabilidad; los y las que estaban en casa de reposo conocieron tasas de contagio y de deceso muy importantes ${ }^{11}$.

Las cuarentenas siempre fueron un desafío. Basta recordar que El Decamerón de Bocaccio tiene como marco una epidemia en Florencia en el siglo xIV y a un conjunto de nobles que,

10 Para contrarrestar estas dicotomías, algunos economistas intentaron mostrar que la sociedad ahorra más dinero salvando vidas gracias a las cuarentenas que lo que pierde por el cierre de empresas. El argumento no tiene gran interés (estudios econométricos similares se han hecho para mostrar los costos negativos de la Revolución francesa...), pero indica la impronta alcanzada por estos razonamientos. Por supuesto, no todos los economistas razonan de una manera tan burda.

11 La cuarentena también fue muy diferente para hombres y mujeres, traduciéndose por una sobrecarga y una pérdida de espacios de independencia más marcados en las mujeres (Singly, 2020). 
aburridos por el encierro, se cuentan historias eróticas para «matar» el tiempo. Sin embargo, se puede hacer la hipótesis que nunca el aislamiento llegó a ser tan vívido como esta vez, y ello no solo por el número de personas que viven solas. Las tecnologías de la información y la comunicación, la revolución digital, los sistemas expertos permitieron imaginar y en parte estructurar una vida social a distancia (delivery, controles administrativos, circulación de ayudas públicas) sin ningún o muy escaso contacto físico. Esta es la infraestructura de la visión de la "vida» propia a la gestión tecno-experta de la pandemia.

La anti-sociología también brilló en las respuestas que algunos intelectuales y expertos se divirtieron en construir para el mundo después de la pandemia. Las propuestas eran conocidas: muy razonables planes anticíclicos (facilitación del acceso al crédito o medidas fiscales); muy recomendables propuestas de relocalización industrial; muy necesarias inversiones en los servicios públicos; muy urgentes proyectos en dirección de la transición ecológica. Nada de todo esto es nuevo u original. Tal vez tampoco se requiere que lo sea. Pero lo que impacta en estos trabajos es otra vez el desliz expertócrata.

El New Deal no fue el fruto de un proyecto intelectual sino de una coalición política (obreros, pequeños propietarios agrícolas, intelectuales y minorias étnicas) que supo aprovechar las oportunidades institucionales y la crisis de un modo de regulación capitalista. Muchas de las propuestas actuales brillan en su brillo tecno-experto por la ausencia radical de toda referencia a las coaliciones de poder capaces e indispensables para instaurarlas. La ingenuidad antisociológica de muchas de estas medidas es sorprendente: la energía desplegada en la formulación de las medidas propuestas contrasta radicalmente con la ausencia de todo esfuerzo en analizar las asimetrías de poder entre los grupos sociales. Si, como lo señalan ciertos analistas, la reactivación económica ocurrirá tal vez más rápidamente de lo que muchos piensan tras la pandemia (por el denominado "rebote» de la economía), es probable que estos proyectos se queden en el cajón del escritorio de los expertos. O que solo se apliquen las medidas compatibles con las asimetrías de poder existentes. Toda crisis es una oportunidad, pero su desenlace es un asunto político.

Esto ya ha empezado a ser visible incluso durante la misma pandemia. Si en un primer momento el papel del Estado fue decisivo para imponer los confinamientos, para instaurar las primeras medidas de sostén de la actividad económica (medidas de desempleo parcial, bonos, etc.), progresivamente la estructura de las sociedades capitalistas hace que el papel central "regrese» al mercado (el Estado volviendo a un papel de soporte de las empresas privadas y de la inversión). El punto es controvertido, pero es plausible que el capitalismo salga reforzado por la crisis sanitaria (Boyer, 2020). Incluso es posible advertir una cierta confusión con respecto a la naturaleza de estas medidas. La mayor parte de los programas sociales implementados en estos meses no son planes keynesianos para relanzar la actividad económica; se limitan a paliar -lo que es esencial- la importante pérdida de ingresos que muchos ciudadanos padecen durante la pandemia o a ralentizar los despidos. Las ayudas públicas diseñadas durante la pandemia son más una manera de sostener la "hibernación» de la sociedad que de relanzar la economía o de incrementar estructuralmente el papel del Estado.

Frente a la pandemia, algunos se ilusionaron con fórmulas utópicas o radicales (el fin del capitalismo, etc.), pero en los hechos es mucho más probable que la vigencia de las estructuras del capitalismo y sus asimetrías de poder desestimen factualmente muchas de las propuestas alternativas formuladas. Otro pecado anti-sociológico. 


\section{DISTANCIAMIENTOS}

Los confinamientos no pueden ser durables, y ello no solo por razones económicas. En América Latina los confinamientos obligatorios "escondieron» el gran número de personas que siguieron trabajando y circulando durante su vigencia, ya sea porque fueron considerados trabajadores esenciales, porque obtuvieron permisos oficiales de manera excesiva, porque hicieron changas, porque desconocieron las reglas, porque simplemente salieron. La gente salió a las calles por múltiples razones que no se reducen a la necesidad económica. En Santiago de Chile, a pesar del confinamiento generalizado, a comienzos de junio la circulación solo había decrecido en un $30 \%$ en los barrios populares y apenas en un 50-60\% en los barrios acomodados. El análisis tecno-experto de estas cifras careció de toda imaginación sociológica: indisciplina social, necesidades económicas, aumentar las sanciones.

La sociabilidad no es un lujo, es una dimensión constitutiva de los seres humanos. La anti-sociología de la gestión tecno-experta de la pandemia simplemente lo desconoció. El equilibrio personal pasa por la sociabilidad - los individuos se sostienen existencialmente porque están sostenidos por un conjunto muy amplio de soportes (Martuccelli, 2007)-. Estos soportes son parte constitutiva de la vida humana; una realidad muy alejada del imaginario de la "vida» sin cualidades de la gestión tecno-experta.

Ante el número de transgresores, se hizo evidente que no era posible reprimir. Esto definió una nueva situación: la necesidad de aprender a convivir con el virus, más allá del confinamiento, en espera de una alta inmunidad de rebaño, una mutación o atenuación del virus o una posible vacuna. El distanciamiento físico entre las personas (mal denominado «distancia social»), no solo fue pues una medida sanitaria que prolonga el confinamiento fue también un compromiso impuesto por las sociabilidades a la anti-sociología de las primeras medidas expertas.

El imaginario del distanciamiento propio a la gestión tecno-experta de la pandemia concibe la sociabilidad desde ángulos exactamente opuestos a la efervescencia, la muchedumbre, la densidad, la masa, los flujos de energía que se producen en los grupos. En breve, todo aquello que ha sido analizado como lo propio de la vitalidad colectiva de las relaciones sociales y del ser-conjunto desde Émile Durkheim (1985) hasta Randall Collins (2009), pasando, entre tantos otros, por Jane Jacobs (1969). Todos los actores requieren y valorizan el contacto, el encuentro, la sociabilidad, incluso si lo hacen desde consideraciones de clase, género, edad y culturales distintas. Una diversidad simplemente ignorada por el confinamiento y por los distanciamientos promovidos de manera generalizada a nivel planetario. En el imaginario tecno-experto la vida social no existe per se. La vida social se piensa como un conjunto disperso de interacciones ocasionales, regulables a voluntad, realizables a distancia física, sin contacto corporal, sin expresión facial abierta. La concepción del individuo como átomo y mónada nunca fue una verdad en el liberalismo clásico (como lo muestran las reflexiones de Adam Smith sobre la empatía), sí lo es en el imaginario de la vida sin cualidades de los tecno-expertos contemporáneos.

Precisémoslo para evitar malentendidos: dado el modo de contagio del covid-19, los confinamientos en un primer momento, las mascarillas y la distancia física son indispensables. Pero esto no agota el debate. Detrás de estas medidas de crisis, subyace un imaginario particular. La idea implícita (y tentadora como tendencia durable para algunos) de una vida social que se estructura sobre nuevas bases: a distancia, gracias a la digitalización, en actividades sin 
contacto, teletrabajo, e-learning, telemedicina, delivery, pruebas deportivas sin público, etc. La gestión tecno-experta de la pandemia no inventó nada de todo esto, pero se apoyó sobre tendencias preexistentes compatibles con su imaginario experto y tiende a perennizarlas en el mundo de la «nueva normalidad» ${ }^{12}$.

Se recomendó así, por ejemplo, el pago con tarjetas bancarias sin contacto y en desmedro de la moneda física - un proyecto tecnocrático de eliminación del dinero físico promovido desde hace años con muy dudosos argumentos de lucha contra la evasión fiscal y el crimen organizado-. Una desmaterialización del dinero que, de realizarse, entrañará modificaciones importantes a nivel de la sociabilidad y tendrá consecuencias significativas no sólo para los más pobres (Haesler, 2018). Se alentó la enseñanza a distancia y no presencial —no solamente como una necesaria respuesta durante las cuarentenas, sino como el horizonte de un nuevo modelo pedagógico y didáctico-. Se promovió el delivery como una manera de reducir la circulación urbana, la contaminación y las agrupaciones (en los mercados, los clientes y vendedores se aglomeran ahí donde hay más gente e incluso cuando se respetó el confinamiento con escasas salidas para las compras, estas se hicieron a veces en mercados que fueron focos de infección), prácticas que se espera se afiancen durablemente por sus positivos efectos a nivel de las emisiones de $\mathrm{CO} 2$. Inútil seguir con la lista. Lo que hay que problematizar, más allá de la cuestión de la eficiencia de estas medidas ante la pandemia, es el imaginario de la vida social que vehiculan. Asistimos a la invención de una suerte de sociabilidad post-social o antisocial, más que de una nueva sociabilidad.

Mucho de todo esto no es nuevo. La compresión del espacio-tiempo, el mundo virtual y los flujos, el primado del espacio sobre el tiempo, la distanciación entre el espacio y el tiempo, el lazo entre lo global y lo local, el problema de la visibilidad: la sociología no ha cesado de analizar estas evoluciones desde la década de 1980 (Harvey, 1989; Castells, 1998; Soja, 1989; Giddens, 1994; Beck, 2004; Heinich, 2012). Pero la gestión tecno-experta no sólo ignoró estas reflexiones, sino que al amparo de la pandemia propuso pasar de experiencias acotadas o dispersas a una experimentación generalizada, engendrando una sociabilidad caracterizada por toda una nueva jerarquía de distancias y de presencias muchas de las cuales (no todas) tienen, en la mirada de muchos expertos, vocación de arraigarse.

Una de las grandes reflexiones de la sociología urbana formulada por la escuela de Chicago mostró la tensión entre la proximidad espacial y la distancia social (Park, 1984; Chamboredon y Lemaire, 1970). La tesis es bien conocida: la contigüidad espacial es insuficiente para garantizar la integración de un colectivo heterogéneo. Sin embargo, a pesar de sus insuficiencias, la proximidad espacial siempre fue reconocida como un factor decisivo (como lo muestran los programas de de-segregación étnica, diversidad social urbana o entre los géneros).

El imaginario social de la gestión tecno-experta de la pandemia es distinto. Su regla de base es casi inversa: distanciamiento espacial y proximidad social. La tensión entre estas dos dimensiones es obliterada. Bajo el imaginario experto una nueva geografía de los afectos se instituye en la cual los hijos y nietos ven a sus padres o abuelos a distancia; una geografía en la cual la proximidad espacial -en principio- pierde todo valor. El postulado es que se puede transmitir la solidez de los afectos a pesar de las distancias.

12 Algo que no concierne a todas las medidas tomadas durante la crisis: por ejemplo, el desencarcelamiento de ciertos reclusos por razones diversas (prisión preventiva, tipo de delitos, vulnerabilidad) no está en la orden del día... 
Como tantas transformaciones, el proceso es ambivalente. Sin duda que muchos actores ahorrarán tiempo en los desplazamientos y que esto tendrá efectos en la contaminación o la reducción de los tiempos perdidos en la congestión urbana; sin duda los dispositivos digitales permiten mantener vínculos sociales y amistades a pesar de las distancias físicas. Pero la tendencia a generalizar este tipo de sociabilidad (a nivel laboral, social, familiar, íntimo) trastoca la naturaleza misma de las actividades sociales que se efectúan. Se puede incluso hablar de una verdadera regresión a nivel de la sociabilidad. La conexión digital hace oficio de interacción social.

El imaginario de una sociedad en la cual se instala una rarefacción de las relaciones sociales no es una fantasía. Es una distopía analizada por ciertas obras culturales y que algunas evoluciones digitales promueven estructuralmente. La comunicación binaria, como afirmó Niklas Luhmann (1995), puede ser la operación de base de los intercambios entre sistemas sociales, pero no puede serlo a nivel de los individuos - estos requieren de la interacción, del contacto corporal, de la expresión facial, de las energías vitales de la sociabilidad, incluso de la mediación sensorial de los objetos (Sacriste, 2018) - . Solo en el imaginario de Facebook un «amigo» es un enlace.

El recurso al indispensable distanciamiento físico como manera de enfrentar la propagación del contagio del covid-19 es, por supuesto, algo muy distinto que el imaginario conectivo del distanciamiento digital generalizado. Sin embargo, el primero amplió el espectro de posibilidad y de expansión del segundo. Y es esto lo que merece atención. Toda crisis es una oportunidad: en ellas se exploran aperturas y tendencias que durante mucho tiempo solo habian permanecido a nivel latente. No es posible presagiar el futuro, pero es posible formular la hipótesis que varias de las modificaciones relacionales que se introdujeron al calor de la pandemia tendrán vocación a prolongarse en el tiempo.

Desde hace lustros, por ejemplo, a pesar de las posibilidades de la videoconferencia, la presencia física del expositor fue considerada como un signo, por implícito que sea, del valor que este le acordaba a la reunión - había decidido estar presente y desplazarse (Jauréguiberry, 2003) - El recurso generalizado a las plataformas de reunión a distancia (Zoom, Google Meet, Skype, etc.) modifica este principio.

Se imponen nuevas reglas y un nuevo imaginario de la proximidad y de la distancia, de lo afectivo y lo impersonal. ¿Es imperioso hacerse visible en una tele-reunión? En muchas instituciones escolares la obligatoriedad se impone a los docentes, no a los estudiantes; en la mayor parte de los centros laborales (pero ni en todos ni para todos), la obligatoriedad de la visibilidad se impone. Aquí también, la evolución en apenas unas décadas es sorprendente. A mediados de la década de 1990, tras algunos meses de ensayo se desestimó en Francia la generalización de los respondedores telefónicos con imágenes de los usuarios. En la época, los clientes manifestaron su recelo ante una tecnología que consideraron intrusiva de su ámbito privado. Treinta años después el imperativo colectivo de la visibilidad simplemente abolió el sentido de esta pregunta y la legitimidad de esta reticencia (Aubert y Haroche, 2011). Generándose y generalizándose nuevas cuestiones de interacción ante las cuales la lógica tecnoexperta es indiferente.

El imaginario conectivo del distanciamiento social digital no es una invención ex nihilo. Más allá de los estereotipos, esta evolución tecnológica es más afín a ciertas sociedades (Estados Unidos, países escandinavos, países asiáticos) que a otras - países latinos o africanos (Gatti, 2020) - . Edward Hall (1985) mostró que las distancias físicas (la proxemia) que los individuos respetan entre si en los lugares públicos varían según las culturas y las sociedades. 
Los imaginarios técnicos nunca son ni cultural ni socialmente neutros. Tampoco lo son los dispositivos digitales. Es así tanto más que su diseño es realizado por un grupo de profesionales (ingenieros, informáticos, diseñadores, matemáticos a fuerte dominante masculina) que, aquí también más allá de todo estereotipo, tienen tendencia a privilegiar modelos altamente conectivos, cuantificados y abstractos de la sociabilidad ("friends», "followers»). En la conceptualización de estos aparatos y su generalización subyace el imaginario de una sociedad transmutada en una yuxtaposición de comunidades virtuales, de vidas pasadas hablando por el celular, mandando y recibiendo mensajes (whatsapp, SMS, twitter, emails), de conexiones a través de pantallas. Todos estos dispositivos son crono-fágicos y banalizan la idea de una vida social saturada de conexiones en desmedro de las interacciones presenciales. La condición digital (Fogel y Patino, 2014) no fue inventada durante la pandemia, pero conoció una profundización y una radicalización inédita durante estos meses, ampliamente incentivada por un cierto imaginario tecno-experto de la vida social.

Por supuesto, se puede argüir que estamos en el momento de invención de una nueva sociabilidad más estructurada por conexiones que por interacciones. 0 , mejor dicho, por un nuevo continuum entre interacciones y conexiones. Las posibilidades abiertas tanto a nivel de integración de la sociedad como en la coordinación de las acciones por el continuum sociotécnico (dispositivos, prácticas de trazabilidad, conductas a distancia) son evidentes y han incluso transformado el viejo debate sociológico entre la integración social y la integración sistémica (Martuccelli, 2017). Además, en las últimas décadas todo un conjunto de trabajos ha mostrado fehacientemente el desarrollo progresivo de distintas comunidades virtuales. No cabe duda de que el sentimiento de pertenencia, las redes sociales, las prácticas de comunicación han sido transformadas por la revolución digital. Sin embargo, todas estas evoluciones presuponían, como un zócalo impensado, la existencia de una sociabilidad interactiva presencial ordinaria. La pandemia ha revelado los limites del "nuevo» imaginario tecno-experto de la sociabilidad-conectiva: en el fondo, todo bien analizado, las conexiones necesitan parasitar a las interacciones. Se puede vivir a través de una sociabilidad interactiva sin conexiones a distancia (una parte sustancial de la historia humana lo testimonia), pero no se puede vivir a través de meras conexiones sin interacciones presenciales.

El imaginario de las conexiones-como-sociabilidad es una variante de la colonización del mundo de la vida por los sistemas expertos (Habermas, 1987). Si su principio operativo de base es distinto (no es ni la economía, ni el poder lo que se promueve, sino la conectividad), el resultado es similar: una desvalorización y desconocimiento del espesor de la vida social.

Las comunidades virtuales son una fecunda dimensión de la realidad social subordinadas, insertas o envueltas en la sociabilidad interactiva; al autonomizarse y generalizarse aparecen como la expresión de un nuevo imaginario anti-sociológico. La pandemia ha tenido el mérito de ponerlo al descubierto llevándolo al límite: la ausencia de vida gregaria dio lugar a un conjunto dispar de resistencias ordinarias que no se limitaron al tema de la libertad ciudadana, necesidades económicas o a humores populistas. A través de la agregación de una miríada de conductas transgresoras de las reglas impuestas (confinamientos y distanciamientos, a veces mascarillas), sin proyecto político explicito, los individuos expresaron apremiantes demandas de sociabilidad interactiva. Esta agregación de conductas y las demandas de sociabilidad presencial que se manifestaron —auténticos «no social movements» (Bayat, 2013) fueron invisibilizadas por otros debates: desde una tonalidad liberal a través de inquietudes por el avasallamiento de las libertades fundamentales por el Estado; desde una tonalidad anti-establishment y anti-elitaria por la acción contestataria de ciertos grupos políticos. 
Pero la dimensión propiamente política no debe soslayar lo que se jugó a nivel del imaginario de la sociabilidad. En esto, la pandemia debe servir como parteaguas para la crítica social. De manera análoga a como lo hace la tesis de la Singularity de Kurzweill (2007) y de los cyborgs (Haraway, 2007) el solucionismo digital (Morozov, 2014) o la vida algorítmica (Sardin, 2015) también existe una fantasía tecno-experta que piensa que es posible hacer reposar (y no solamente mediar) la vida social sobre la conectividad digital. Contra estas ilusiones distópicas es importante defender normativamente el hecho de que la materia prima de la vida social es la sociabilidad interactiva co-presencial.

Durante la pandemia, surgió una nueva categoría: los trabajadores esenciales. Los que estaban en "primera línea» en la "guerra» contra la pandemia o que fueron considerados «indispensables» para el funcionamiento de la vida social. Incluso dejando de lado la diversidad de las clasificaciones nacionales (en ciertos países, por ejemplo, las actividades bancarias fueron consideradas esenciales, pero no en otros), uno de los grandes rasgos definitorios de muchos empleos esenciales fue la necesidad de una co-presencia física. Eran la verdadera infraestructura relacional del ser-conjunto. Primera sorpresa: lo esencial es justamente lo que el imaginario tecno-experto buscó erradicar durante la pandemia y que de alguna manera se busca prolongar como ideal de sociabilidad.

La durabilidad de esta categoría (y su traducción en términos salariales) es poco probable, pero el análisis de los principios de esta división laboral es instructivo. Entre los esenciales hubo una gama muy amplia de empleos con remuneraciones, calificaciones y estatus muy diferentes (médicos, enfermeros, auxiliares, delivery, recolectores de basura, negocios de primera necesidad, farmacias, policías, bomberos, etc.). Sin embargo, más allá de esta diversidad, lo común fue el carácter presencial irreductible de la actividad. Fue un gran momento de confesión pública: muchos de los trabajadores peor pagados, más intercambiables, con menor protección, cuyos empleos eran definidos -erróneamente- como poco calificados se convirtieron en esenciales. La prueba de que algo no anda bien en las jerarquías laborales.

No fue el único ejemplo. La inadecuación estatutaria entre actividades también se reveló a propósito de los empleos que podian ser o no efectuados a distancia. Centrémonos en dos casos. Por un lado, la medicina. La generalización de la telemedicina, que se expandía desde antes de la pandemia, será sin duda acelerada por ella. Y lo será, en parte, porque la actividad médica ha sido descalificada en las últimas décadas a medida que se tecnificó. Pero también porque, de hecho, las visitas médicas hacen oficio de sociabilidad para muchos individuos, de la misma manera que los servicios de urgencia hospitalarios se han convertido en una muy importante institución de gestión de la exclusión social. El prestigio del cuerpo médico, su poder corporativo y el relativo maltusianismo del número de médicos han frenado las consecuencias estatutarias que implica el desplazamiento de la clínica por una letanía de análisis. Con la creciente afirmación de la telemedicina se desconocerá aún más de lo que ya es el caso las necesidades de sociabilidad específicas de los pacientes.

El otro caso es el de la educación. A pesar de ingentes esfuerzos (e-learning, moocs, teleenseñanza, etc.) la relación pedagógica continúa siendo de índole fuertemente presencial. Ciertamente, las aulas se equiparon de proyectores y las clases se estructuraron cada vez más a través del powerpoint, pero la relación educativa exige la co-presencia (algo que las pedagogías y didácticas participativas refuerzan). A pesar de los intentos por descalificar el trabajo docente desde la década de 1980, la complejidad de la relación educativa (a dife- 
rencia de muchas prestaciones médicas) impidió esta evolución (Barrère, 2017). Más allá de la actividad docente propiamente dicha, además, la educación (desde las guarderías hasta la universidad) es inseparable de los pares y de la sociabilidad infantil, adolescente, juvenil. Si la educación no se reduce a la sociabilidad, no hay educación sin sociabilidad presencial entre pares.

Esto es lo que millones de alumnos ya sabían, esto es lo que muchos padres de familia recordaron. Los alumnos no van a la escuela solamente para permitir, liberándolos de su cuidado, el trabajo de los padres. La co-presencia en los centros educativos es el factor decisivo de la educación. Sin embargo, ciertos actores, por motivaciones diversas (económicas y tecnoideológicas) cuestionan esta evidencia. La pandemia les sirve de coartada. Si las clases pudieron dictarse a distancia durante semanas ¿por qué no perennizar esta modalidad de relación pedagógica? La tentación es particularmente fuerte a nivel de las universidades en donde existe en varios países el proyecto de diferir o limitar durablemente el retorno a clases presenciales, y esto en abierto contraste con la apertura de bares, restaurantes, comercios, estadios. A pesar de ello, la toma de conciencia de la importancia de la presencialidad escolar se impuso progresivamente haciendo que en algunos países - más en Europa, menos en América Latina- el retorno a las aulas se haya vuelto un imperativo (casi similar al del trabajo) en la gestión de la pandemia.

Sin que pueda generalizarse a todos los empleos, la diferencia entre estos dos oficios puede resumirse en una fórmula: ahí donde la medicina se caracteriza cada vez más por una alta complejidad técnica y baja complejidad relacional (delegada a enfermeras y auxiliares), la enseñanza brilla por su relativamente baja complejidad técnica y su alta complejidad relacional. Detrás del conflicto latente entre estatus laborales, se encuentra un conflicto de imaginarios: actividades que desvalorizan lo presencial y actividades que por el contrario valorizan la co-presencia, el contacto, la sociabilidad (por supuesto toda la filosofía del care y los cuidados).

Las crisis revelan el trabajo de las estructuras. La gestión de la pandemia del covid-19 no deroga esta regla. Con el tiempo, cuando se pierda en el recuerdo muchas de las decisiones coyunturales tomadas, quedará en los hechos el vigor de la manera como se desplegó, profundizó y radicalizó un imaginario tecno-experto.

Teniendo en cuenta lo anterior, el objetivo de este artículo bajo la forma de un conjunto de reflexiones críticas ha sido doble. Por un lado, problematizar la continuidad que en los imaginarios subyace entre la gestión tecno-experta de la pandemia y ciertas posibles evoluciones futuras en los lazos sociales. Por otro, perfilar detrás de esta continuidad uno de los grandes desafíos de las sociedades contemporáneas: el conflicto larvado, pero decisivo, entre visiones tecno-expertas profundamente anti-sociólogicas en sus presupuestos y las realidades de la sociabilidad en tanto que pilar de la vida individual y colectiva. Se trata de una de las grandes luchas contemporáneas: aquella que opone a los conocimientos descontextualizados (indicadores, shock económico, best practices, benchmarking, pruebas estandarizadas, confinamientos planetarios homogéneos) contra la sabiduría contextualizada. En este combate, a pesar de su crisis y de la postergación de la que es objeto, la sociología sigue siendo una de las grandes guardianas de esta última y venerable tradición de saber. 


\section{BIBLIOGRAFÍA}

AA.VV. (2020). Sopa de Wuhan. Sin/lugar: Editorial ASPO.

Aubert, N., y Haroche, $\mathrm{Cl}$. (2011) (eds.). Les tyrannies de la visibilité. Toulouse: Erès.

Barrère, A. (2017). Au cœur des malaises enseignants. Paris: Armand Colin.

Bayat, A. (2013). Life as politics. Stanford: Stanford California Press.

Beck, U. (2004). ¿Qué es la globalización? Barcelona: Paidós.

Boyer, R. (2020). Les capitalismes à l'épreuve de la pandémie. Paris: La Découverte.

Callon, M., Lascoumes, P., y Barthe, Y. (2001). Agir dans un monde incertain. Paris: Seuil.

Castells, M. (1998). La société en réseaux. Paris: Fayard.

Chamboredon, J.-C., y Lemaire, M. (1970). Proximité spatiale et distancia sociale. Les grands ensembles et leur peuplement. Revue française de sociologie, 11(1), 3-33.

Collins, R. (2009). Cadenas de rituales de interacción. Barcelona: Anthropos.

Durkheim, E. (1985). Les formes élémentaires de la vie religieuse. Paris: PUF.

Esposito, R. (2004). Bios. Turin: Giulio Einaudi Editore.

Fogel, J.-F., y Patino, B. (2014). La condition numérique. Paris: Points.

Gatti, G. (2020). Desde la ventana de mi refugio. Pequeñas historias de urgencia desde Palo Alto, CEMI, 4 de mayo.

Giddens, A. (1994). Las consecuencias de la modernidad. Madrid: Alianza.

Habermas, J. (1987). Théories de l'agir communicationnel (2 tomos). Paris: Fayard.

Haesler, A. (2018). Hard modernity. Paris: Editions Matériologiques.

Hall, E.T. (1985). La dimensión oculta. México: Siglo XXI.

Haraway D. (2007). Manifeste Cyborg et autres essais. Paris: Exil Editeurs.

Harvey, D. (1989). The Condition of Postmodernity. Cambridge: Basil Blackwell.

Heinich, N. (2012). De la visibilité. Paris: Gallimard.

Jacobs, J. (1969). Economies of Cities. New York: Random House.

Jauréguiberry, F. (2003). Les branches du portable. Paris: PUF.

Kurzweill R. (2007). Humanité 2.0. Paris: M21.

Luhmann, N. (1995). Social Systems. Stanford: Stanford University Press.

Martuccelli, D. (2007). Gramáticas del individuo. Madrid: Losada.

Martuccelli, D. (2010). Critique de la philosophie de l'évaluation. Cahiers internationaux de sociologie, CXXVIII-CXXIX, 27-52.

Martuccelli, D. (2017). La condition sociale moderne. Paris: Gallimard.

Martuccelli, D. (2020). La nouvelle solitude de l'Amérique latine. Cités, 84, 95-110. 
Mora, R., y Tironi, M. (2020). ¿Distanciamiento social? Lazos sociales en tiempos de crisis. El Mostrador, 5 de junio. htps://www.elmostrador.cl/noticias/opinion/ columnas/2020/06/05/distanciamiento-social-lazos-sociales-en-tiempos-de-crisis/

Morozov, E. (2014). Pour tout résoudre cliquez ici. Paris: FYP Éditions.

Park, R.E. (1984). La ville comme laboratoire social. En Y. Grafmeyer y J. Isaacs (eds.). L'école de Chicago (pp.163-180). Paris: Aubier.

Passeron, J.-C. (1991). Le raisonnement sociologique. Paris: Nathan.

Sacriste, V. (2018). Nos vies, nos objets. Villeneuve d'Ascq: Presses Universitaires du Septentrion.

Sardin, E. (2015). La vie algorithmique. Paris: L'Échappée.

Singly, F. de. (2020). Le confinement a été révélateur des inégalités qui structurent la vie familiale. Le Monde, 20 juin. https://www.lemonde.fr/societe/article/2020/06/19/ le-confinement-a-ete-revelateur-des-inegalites-qui-structurent-la-viefamiliale_6043416_3224.html

Soja, E. (1989). Postmodern Geographies. London: Verso.

Tarragoni, F. (2019). L'esprit démocratique du populisme. Paris: La Découverte. 